\title{
MORAL DA POLÍTICA E ANTROPOLOGIA DAS RELAÇÕES DE PODER NO SERTÃO DE PERNAMBUCO*
}

Jorge Mattar Villela

\section{Apresentação}

O Sertão de Pernambuco é historicamente conhecido pelos seus malfeitos. Ainda quando os malfeitos tornam-se folclore. Ao contrário do Ceará e de outros estados nordestinos, Pernambuco não costuma ser apontado como um dos focos de fome e miséria que de tempos em tempos assola o interior dessa região. Cangaceiros e salteadores de estradas, indígenas rebelados, vinganças de sangue, brigas de família, sedições; estas eram as preocupações dos governos estaduais e dos responsáveis pelas forças policiais durante a Primeira República (Villela, 2004). Os discursos das autoridades acerca destes distúrbios - situados entre ameaças à ordem pública e à segurança individual - efetuaram uma

\footnotetext{
- Uma versão deste artigo foi apresentada no Simpósio de Antropologia "Entre o legal e o ilegal", realizado no Programa de Pós-Graduação em Antropologia Social da UFSCar em 2008. Gostaria de agradecer a todos os participantes que comentaram e propuseram ideias para melhorá-lo. A responsabilidade pelos equívocos, como se sabe, é minha. Manifesto minha gratidão também aos meus amigos de Jordânia e à juíza e à promotora daquela comarca pela generosidade, recepção e colaboração irrestrita com esta pesquisa. Os dados necessários para este artigo não teriam sido coletados sem a ajuda deles.
} 
divisão entre o Pernambuco contemporâneo destes agentes de enunciação e o Pernambuco pretérito, atrasado. Relegada ao passado eterno, submetida a uma ordem social antiquada e inadequada ao tempo presente, assim permanece aquela região, segundo os demais agentes de enunciação que se multiplicaram ao longo das décadas: juristas, jornalistas, cientistas políticos, sociólogos, historiadores. Apenas os antropólogos não o fizeram, mas talvez por falta de oportunidade ${ }^{1}$. Ainda na Primeira República, o Sertão foi posto na parte de lá do muro que separa modernidade e tradição. Uma vida diferente, homens rústicos, uma região violenta, um outro tempo. "Alocronismo" (Fabian, 1983): uma temporalidade que simultaneamente nega coevidade a certos grupos humanos, como, por exemplo, os "primitivos" e as populações "tradicionais", sobretudo as camponesas, e convive com a exigência metodológica da pesquisa que situa num mesmo tempo pesquisadores (modernos) e pesquisa164 dos (tradicionais ou primitivos).

As autoridades estaduais esforçaram-se para distinguir-se dos potentados locais. Elas se consideravam modernas, democráticas e legais, em oposição a eles, arbitrários, antiquados e ilegais. A distinção traçava-se por critérios geográficos, calcados sobretudo nas teses do isolamento. Os defeitos das suas instituições foram debitados nas contas dos chefetes de campanário ${ }^{2}$ : impunidade, promiscuidade entre policiais e civis, precariedade da situação geral dos municípios, proteção a criminosos. Mas foram debitados também à suposta ignorância da população e ao mau uso que faziam da instituição do júri. Relações inadequadas entre regras jurídicas e costumes locais provocaram,

\footnotetext{
${ }^{1}$ A primeira etnografia sobre o Sertão de Pernambuco foi escrita em 2001 e publicada em 2002 (Marques, 2002).

${ }^{2}$ As palavras ou expressões que aparecem em itálico, salvo por aquelas em língua estrangeira, fazem parte do repertório de termos, noções e conceitos nativos.
} 
dizia-se então, o domínio das primeiras pelas últimas e uma situação geral de insegurança.

O temor que o Sertão desperta atualmente (ou ao menos despertava há poucos anos) na população litorânea é, portanto, cultivado há décadas e alimentado diariamente. Tráfico de drogas, assaltos a cargas nas estradas, pistoleiros de aluguel e brigas de família, ao lado das tragédias provocadas pelas secas (de resto, segundo meus colaboradores locais de pesquisa, hiperbolizadas pelos jornalistas), são os únicos temas que permitem ao semiárido pernambucano sair do anonimato em que está imerso. Os habitantes das demais regiões do país, raramente ouvimos falar do Sertão de Pernambuco se a notícia não remete às páginas policiais e às tragédias climáticas.

Mesmo recentemente, os estudos sobre o Sertão mantiveram-se sob o domínio deste antigo discurso, das teses veterorrepublicanas que engendraram noções hegemônicas nas nossas ciências sociais, como as de coronel e coronelismo. As teses do isolamento, irmãs das teses presididas pelo princípio do "alocronismo", atravessaram as décadas, explicando a violência, a sociedade e a política sertaneja (ainda que possivelmente nenhum cientista social tenha pesquisado na região ${ }^{3}$ ). Explicações que não raro esbarram em diversos problemas que poderiam ser esquematizados da seguinte maneira: 1) elas desembocam necessariamente numa topologia do poder cristalizado no monopólio ou no controle dos recursos por uma classe, por um grupo, ou em certos casos, por um indivíduo (tese da oligarquia); 2) elas reduzem a uma relação diádica uma multiplicidade de fatores que ligam patrões a clientes

\footnotetext{
${ }^{3}$ Um exemplo particularmente claro desta má compreensão pode ser visto em Pandolfi (1986). Não seria justo nem honesto, porém, generalizar a abordagem da ciência política brasileira acerca da política eleitoral do Sertão de Pernambuco a partir deste trabalho já antigo e mal formulado.
} 
(tese do binarismo); 3) elas submetem todas essas relações à circulação de bens e serviços, ao traduzir para o idioma da reciprocidade as diversas motivações que mantêm vivas as solidariedades polimorfas e multifuncionais existentes (tese troquista).

Muito pânico tem sido infundido ao se descreverem as relações evidentes, possíveis ou veladas entre violência e política eleitoral. Na história moderna, a democracia e as nações foram construídas com carne e sangue, à base de limpeza étnica e restrições civis; quer no ocidente, quer no extremo oriente moderno. Para usar a terminologia de Tambiah (1996) ao falar do sudeste asiático, não é raro que os Estados-nação derivem para formas violentas de etnonacionalismo. A democracia, como uma dentre muitas formas de governar os homens, supõe alguma carga de violência superficial ou profunda, assim como exige alguma escroqueria nos mais diversos níveis de intensidade ${ }^{4}$.

166 Por este motivo, seria ingênuo dedicar ao Sertão, ao Nordeste, ao Brasil, um estudo que enfatize as relações da violência com as eleições. Porque isso poderia ser feito, como de fato o foi, para os EUA das décadas de 1980 e 1990 (Jankowski, 1991). Seria igualmente injusto dedicar àqueles mesmos lugares estudos cuja ênfase repouse na patronagem ou no clientelismo. Há muito tempo, isso poderia ser feito, por exemplo, para o Canadá (Lemieux, 1970). Seria, preconceituoso, por fim, circunscrever os estudos políticos sobre o nepotismo apenas aos meus colaboradores locais de pesquisa. De algum modo, comedido decerto, isso tem sido feito para o caso francês (Abèles, 2001; 2002).

Na melhor das hipóteses, mesmo se não se emprega este termo, compreende-se que justiça, política ou democracia representativa sofrem processos de vernaculariza-

\footnotetext{
${ }^{4}$ A respeito de uma thanatopolítica paralela ao biopoder, ver Foucault (entre outros lugares, 1985, pp. 129-133).
} 
ção em ambientes "tradicionais", assim como Michelutti (2007) defende para o caso da Índia. Ou seja, em meio ao ideal democrático, encontram-se variantes (a indiana, para Banerjee, 1999; a brasileira, para Mayer e Weatherhead, 1964, são dois exemplos importantes), encaradas como arcaísmos, desvios, corruptelas, misturas do ideal às práticas locais etc. Uma quantidade importante dos escritos que se podem classificar sob a rubrica de uma "antropologia da democracia" (Paley, 2002) trabalham nos termos de um choque entre o que estava (as práticas políticas "tradicionais") e o que chegou (os "ideais democráticos"), seja nos períodos de redemocratização (Taylor, 1993; Schirmer, 1998; Aretxaga, 2000), nos pós-coloniais (West, 1998; Shaffer [1997] apud Paley, 2002); Comaroff e Comaroff, 1997), nos pós-socialistas (Bellier [2000] apud Paley, 2002; Burawoy et al. [1999] apud Paley, 2002). São iniciativas, portanto, semelhantes às de Geertz (1963), estimuladas por seu conceito de "sentimentos primordiais" (endógenos ou autóctones) em choque com o novo ordenamento cívico (o democrático, exógeno e alóctone, portanto). Talvez a única e pequena alteração de lá para cá, ao menos em língua inglesa, tenha sido a ênfase na interpretação da democracia ocidental pelas instituições ou pelas tradições nativas (Gershière, 1997; Herzfeld, 1985; Yashin-Navaro, 2007).

No caso da variante brasileira, como se sabe, atribui-se à família patriarcal (carregada de todo o sal da violência, da imposição, da biologia) o seu traço diacrítico ${ }^{5}$. Trata-se, portanto, de um intruso nos ideais da democracia representativa, universalista, cuja modernidade construiu-se empregando suas formas usuais de purificação: limpeza étnica para os povos, "limpeza ontológica" para as ideias (Almeida, s. d.).

\footnotetext{
${ }^{5}$ Aqui as referências seriam inúmeras e repetitivas; bastará, parece-me, visitar Duarte (1966); Candido (1951); Freyre (1964). Para uma abordagem sintética do problema, ver Corrêa (1994).
} 
Já há tempos antropólogos e outros cientistas sociais apontam para esta prática dos Estados-nação: extirpar do que consideram práticas políticas outros aspectos da vida social (Herzfeld, 1992; Kuper, 1988; Fabian, 1983; Carrier, 1995; Donzelot, 1986; Nathan, 2001; Jullien, 2008). O Ocidente moderno tentou livrar-se da agência das coletividades familiares em suas outras zonas de atividade, como, por exemplo, a política. Procurou, com êxito, se aderirmos às teses de Donzelot (1986, pp. 47 e passim), desenraizar a família de suas conexões coletivas, acompanhando a fabricação do indivíduo moderno. Esforçou-se, enfim, para reduzir sua ação política a um grau próximo de zero, assim como minimizar a ação política dos indivíduos, agentes políticos intermitentes nas democracias modernas, circunscrevendo-a à região em que podia atuar a Razão, este grande soberano na Idade Moderna ${ }^{6}$. A crença nestas purificações - as distinções operadas entre a Democracia e as práticas políticas, 168 associadas àquelas de colonização e dominação entre Estados -, forneceu muitas vezes as condições necessárias para as elaborações de escalas de perfeição baseadas antes nos ideais do que na diversidade das práticas. Assim, em certos casos, observam-se análises das práticas dos países centrais identificados aos ideais democráticos e suas respectivas falhas associadas às práticas dos países periféricos: más cópias dos primeiros, corruptelas suas.

A antropologia política processualista, que sucedeu a estrutural-funcionalista inglesa, estabeleceu métodos novos de pesquisa para o estudo da política em sociedades complexas ${ }^{7}$. Sua proposta, como se sabe e em linhas

\footnotetext{
${ }^{6}$ A respeito desta última operação, ver Garrigou (1988).

${ }^{7}$ Boissevain e Mitchell (1973) fazem uma crítica ao estrutural-funcionalismo logo na primeira página da sua coletânea, baseada na visão estática, corporativa e juralista da sociedade, segundo seus críticos, formulada por essa escola. Outras críticas ao estrutural-funcionalismo e propostas processualistas aparecem em outras coletâneas clássicas: Banton (1966), Swartz et al. (1966), Swartz (1968), Eisenstadt e Roniger (1984), Gellner e Waterbury (1977) e Schmidtt et al. (1977).
} 
muito gerais, era substituir a primazia da estabilidade pela da mudança, dos grupos corporados pela das redes e ligações interindividuais diversas, e, enfim, do equilíbrio pela do conflito. É curioso notar que os processualistas não procuraram criticar a abordagem alocrônica dos funcionalistas, ao enfocar seus estudos tanto em zonas periféricas do mundo democrático (Mediterrâneo, Ásia, América Latina) quanto nas franjas de legalidade. Se por um lado a legalidade fora substituída em certos casos etnograficamente pela legitimidade dos territórios ou das comunidades morais, as práticas descritas nos mais diversos trabalhos navegam em águas suspeitas; ora na raia da patronagem e do clientelismo, ora na da corrupção estrita. Por outras palavras, conforme já se notou (Goldman, 2007), as redes que descrevem muitos dos processualistas falam de funcionamentos contraventores dos princípios universalistas da democracia representativa. O problema central, parece-me, é que a junção do objeto empírico com a abordagem propriamente dita, mais o conjunto nocional acionado, induzem preconceitos já instaurados anteriormente à pesquisa. A antropologia processualista foi mais uma pá a cavar o fosso entre os de lá e os de cá, a demonstrar a má qualidade de certas cópias quando cotejadas com seus originais euro-americanos. Enfim, salvo raras e honrosas exceções (Gershière, 1997 e Yashin-Navaro, 2007; 2009), assim se tem feito antropologia da democracia. Se acreditarmos no artigo recapitulativo de Paley (2002), pouco se realizou em antropologia de língua inglesa que escape a este modelo.

Aqui se situa certamente um dos problemas da minha própria pesquisa. Compra e venda de votos, pistolagem, corrupção; ali, onde a fama antiga de contravenções de toda ordem fermentou-se na história bem-sedimentada pelos discursos imponentes dos grandes juristas formados na Faculdade de Direito de Pernambuco e regada cotidiana- 
mente pelos célebres nomes da ciência social de toda parte (Leal, 1997; Freyre, 1964; Queiroz, 1976, para citar apenas os mais célebres e mais fundantes, em que pesem as suas diferenças de abordagem, objetivo e enfoque, e estarem em times adversários na história da sociologia brasileira). São assuntos problemáticos para quem não pretende colher os frutos do preconceito. Conforme me perguntaram alguma vez, por que o Sertão? Não seria mais indicado, por exemplo, Nova Iorque? Decerto, porque seria possível mostrar, lá nos Estados Unidos, práticas que ressoam no interior de Pernambuco, que são detectadas sem observação por profissionais de toda natureza quando pretendem deixar de fora do presente esse ou aquele coletivo humano. Mas se me livro (ou os livro a eles, sertanejos) do arsenal conceitual do processualismo, do juralismo, do Estado-nação, da teoria política, dos modelos e das cópias, e me submeto à própria expertise dos meus colaboradores locais de pesquisa, tudo 170 mudará de figura, a meu ver ${ }^{8}$ : lançar mão do método de pesquisa intensiva de campo, reforçando o domínio empírico sem o substantivar, do estilo etnográfico de apresentação; enfim, levar a sério os conceitos e as teorias nativas. De resto, trata-se de uma promessa formulada pela antropologia da democracia de Paley (2002), cuja realização não me parece plena nos trabalhos dos autores que o artigo se encarrega de expor.

Se o fosso entre "nós" e "eles" é cavado com mais ou menos vigor ainda por aqueles que pretendem criar pontes entre as margens, o mesmo ocorre no que toca a diversos intervenientes nos processos eleitorais, sobretudo os

\footnotetext{
${ }^{8}$ Por outras palavras, trata-se de assimilar em minha pesquisa as recomendações sugeridas pelo projeto do Núcleo de Antropologia da Política (NuAP, 1998) e por alguns dos antropólogos cujas pesquisas foram norteadas mais ou menos proximamente a esta proposta (Palmeira 1992; 1996; Palmeira e Heredia, 1993; Chaves, 2003; Goldman, 2007; Marques, 2002; 2003). Para uma reflexão sintética do problema da família, da política e da violência, ver Marques et al. (2007).
} 
representantes da justiça. A breve etnografia que aparece adiante pretende mostrar como se comportam os lados que se formam quando um deles pretende isolar-se do outro e ao mesmo tempo construir uma imagem de si mesmo como educador. O resultado esperado não é uma espécie de comédia dos erros, mas a possibilidade de aliar o estudo antropológico da política com o exercício de uma antropologia das relações de poder que substituiria um ensaio de antropologia da moral ou das moralidades. Antes, portanto, talvez seja necessário fazer uma pequena reflexão acerca deste último aspecto.

\section{Uma moral e várias moralidades?}

$\mathrm{O}$ que se pode entender por antropologia da moral e o que há de novo nesta expressão para uma atividade do saber forjada em boa medida pelo pensamento durkheimiano cujo último objetivo (considero o de maior importância) era precisamente o de elaborar uma ciência da moral? De pouco adiantará, parece-me, a ligeira substituição da palavra moral por moralidades. Assim, no lugar de uma antropologia da moral, teríamos uma antropologia das moralidades, a saber, aquela que substitui o singular, absoluto e universal pelo plural, relativo e cultural. A tarefa empreendida por Boas, a seguir-se o influente artigo de Stocking Jr. (1968) e que derivou no relativismo cultural norte-americano, embora tenha reconhecido o valor das diversas culturas, preservou intacta a crença em valores universais. Crença que subverteu de certo modo o projeto antropológico boasiano convertendo-o em antropologia aplicada (Yans-McLaughlin, 1986).

Se é insuficiente o movimento de transformar a moral em moralidades, será preciso, então, levar às últimas consequências a tarefa de um relativismo moral; ato perigoso para certos casos de pesquisa. A começar por relativizar, não a moral ou as moralidades dos demais, mas a nossa 
própria ${ }^{9}$. Relativizar os nossos universais: Direitos Humanos, as noções de Justiça, Bem, Igualdade e, para o nosso caso particular, a Democracia. Seria preciso, de fato, fazer uma antropologia menos humana, demasiado humana. $\mathrm{Ou}$, por outras palavras, tomar como objeto de pesquisa, no sentido forte da expressão, aqueles que, formados pelo tripé grego, romano e cristão, formularam para nós, sob a égide da filosofia (o logos, o conceito, o saber), da justiça (a lei, a cidadania, o Gênero Humano) e da religião (a evangelização, o espírito, o amor), os nossos universais (Jullien, 2008, pp. 69 e passim) ${ }^{10}$. Por outras palavras, as de Michel Foucault, seria preciso fazer ao mesmo tempo mais e menos do que uma história ou antropologia social, mais e menos do que uma análise formal do pensamento. Seria preciso simultaneamente desnaturalizar e desuniversalizar a existência humana (Foucault, 1994d, pp. 777 e ss.). Ou ainda, reconhecer a existência de uma formação históri-

172 ca da humanidade pelas práticas e pelos saberes segundo processos obscuros (porém não escamoteados, ao contrário, obscuros porque excessivamente expostos, habitualizados) de produção das categorias universais do pensamento (Foucault, 1994d, pp. 777 e ss.).

Vejamos, por exemplo, os que estudam o que Schneider e Schneider (2008) chamaram de "antropologia do crime e da criminalização". Nas pesquisas sobre o crime, temos o par segurança pública/estudos da violência, embora o segundo termo não seja consolidado para os que não pretendem que suas pesquisas sejam aplicadas ou contribuições para

\footnotetext{
${ }^{9}$ Outra vez, é provável que a grande iniciativa seja ainda a de Jullien, ao esforçarse por pensar as obras dos que fundaram para nós uma moral, os filósofos iluministas, num diálogo com a filosofia clássica de Mêncio (Jullien, 2001).

${ }^{10}$ Talvez os primeiros enunciados a esse respeito no século XX, embora com material, objetivo e foco distintos, tenham sido os de Foucault (1994b, pp. 473 e ss.). Em linhas muito gerais, Foucault diz a Chomsky, então defensor de alguns universais da natureza humana, que esta última é uma fabricação histórica, assim como todos os universais. Assim, portanto, é a própria noção de natureza humana.
} 
órgãos de segurança pública melhorarem o seu funcionamento, incrementarem a sua eficácia, humanizarem os seus procedimentos. É bem sabido e pouco discutido que muitos destes pesquisadores escrevem as suas etnografias temerosos das acusações de que podem ser alvos, provenientes de atiradores situados em várias frentes. Que se despreze o fundado ou o infundado destas suspeitas e temores. Atualmente, imagino, as sugestões de pesquisa de alguns antropólogos colaboradores do curioso Fieldwork under fire (Zulaika, 1995; Sluka, 1995) parecem inexequíveis para qualquer antropólogo cuja pesquisa verse sobre violência no Sudeste, ou, para falar apenas do que sei, no estado de São Paulo. Apenas para recordá-las, parecia criticável a estes autores que as etnografias da violência só dispusessem relatos, sem que os etnógrafos dispusessem eles mesmos da oportunidade de testemunhar atos violentos provocados pelas pessoas entre as quais faziam pesquisas. Abrir mão do relativismo moral, ou seja, julgar, mesmo, os atos reprováveis à luz da nossa justiça, da nossa moral, seria para um antropólogo desistir de um dos princípios da profissão. Por outro lado, haverá quem defenda, com Carrithers (2005), um ato de prestidigitação neste dilema: relativismo cultural, sim; relativismo moral, não. Os que estiverem de acordo com Overing (1985, p. 17) e entenderem que não há produção de conhecimento humano que não esteja atrelado a uma produção moral correlativa haverão de se queixar. Enunciado que não é redutível ao de Foucault, para quem, como se sabe, todo regime de saber estabelece uma relação de retroalimentação com exercícios específicos de poder ${ }^{11}$. Foucault também estava

\footnotetext{
${ }^{11}$ A esse respeito, ver um pouco por todo lado na obra de Foucault entre 1970 e 1981. Os lugares mais nítidos, talvez, conforme aparece na bibliografia, sejam Foucault (1978) (onde o autor expõe logo na primeira conferência as condições conceituais de possibilidade para que se faça uma história da verdade e uma história crítica do sujeito) e Foucault (1975; 1997; 2004a; 2004b). Será preciso lembrar, por exemplo, de reflexões como as que associam o despertar das preocupações
} 
atento à produção "interessada de conhecimento", distante dos postulados da metafísica clássica. Foi este interesse nas possibilidades de produção de um sujeito de conhecimento uma das vias que levaram tal autor a investigar as relações entre sujeito e verdade (Foucault, 2001, pp. 4-20).

Se seguirmos as formulações de Foucault, a história do pensamento ocidental (aí imbricadas todas as exigências das relações de poder, de violência e de violação) fabricou para nós a ideia de que a guerra ou a violência são estados de disfunção, anormalidade ou anomalia sociais, uma relação negativa:

“a agressão ou a hostilidade não são condições sociais de que temos necessidade para forjar subjetividades e nossa identidade nos planos individual e coletivo [...] sabemos também que o peso da Lei é enormemente convocado para enquadrar este fenômeno"

e, ainda, quando tais fenômenos ocorrem, "julgamos que introduzem e exprimem um problema no curso normal da socialização” (Taylor, 2006, pp. 68-69). A crítica interna a nós mesmos elaborada por alguns antropólogos mistura ingredientes externos - os outros povos, as outras ontologias, as outras morais -, no lugar de uma tentativa de formular uma crítica desde dentro, como é o caso de Foucault. Para Taylor, seria preciso verificar o modo como os Jivaro exigem práticas a nossos olhos violentas como modos de produção das suas subjetividades. Eis aí, portanto, a relativização da nossa moral em confronto a outras moralidades e produções de saberes.

sociológicas com o suicídio às exigências de uma nova relação dos poderes com a vida, a emergência da biopolítica (Foucault, 1985, p. 130), mas também das dificuldades de se fazer ciências sociais desligadas destas mesmas preocupações em função do problema, daí resultante, concernente às relações Indivíduo/Sociedade. Sobre este último aspecto, ver Foucault (1994d, p. 818). 
O mesmo se pode falar acerca dos que estudam Direitos Humanos $^{12}$, democracia e relações de gênero. Por exemplo, sempre se pode perguntar o que podem fazer os antropólogos diante do apedrejamento de mulheres, do infanticídio de meninas, da ablação do clitóris ou do uso da bur$\mathrm{ca}^{13}$. Nestes casos, a hesitação entre a tutela e o abandono, entre a condenação moral e a negligência é sempre a única situação possível? E quando se trata do que se chama corriqueiramente de mercantilização dos votos, de corrupção, de nepotismo, de "uso da máquina"? O que fazer? Hesitar sempre entre duas posições (a da indiferença dos modernos em relação ao atraso, à ignorância e à superstição; a condenação moral ou legal)?

Enfim, o que fazer com o seguinte problema: dado este curioso traço do etnocentrismo ocidental, o proselitismo, como fazer antropologia ao mesmo tempo desviando-se dos nossos valores morais universalizados (Democracia, Liberdade, Razão, Estado, Humanidade, Paz, Bem) e das acusações de relativismo moral? Fassin (2008, pp. 333-334) reivindica uma antropologia da moral distinta de uma antropologia moralista; seja de si mesma, seja dos demais - assim como uma antropologia política não ensina a votar e uma antropologia médica não cura, da antropologia da moral não se exigirá a proposta de um "código de boa conduta ou um guia para uma sociedade melhor" (Fassin, 2008, p. 334). Partir da ciência moral baseada em relatos etnográficos, para usar a expressão de Fassin, e prolongar a sua reflexão e a sua proposta, exige que se inclua como objeto de pesquisa

\footnotetext{
${ }^{12}$ Será preciso enfatizar a relevância para os antropólogos do recente livro de Jullien (2008), embora haja uma vasta literatura antropológica sobre o tema. Mais interessante é que talvez Jullien tenha sido dos poucos a fazer uma antropologia de nós mesmos quando o assunto é Direitos Humanos e não ser um mero militante. Fazer relativismo de nós mesmos é a principal tarefa, não declarada, do sinólogo François Jullien.

${ }^{13}$ A respeito deste último problema, ver Abu-Lughod (2002).
} 
e descrição os preconceitos morais do mundo do pesquisador ao mesmo tempo que os do mundo do pesquisado. A proposta de Fassin culmina na inclusão dos preconceitos morais do antropólogo como "objeto de sua pesquisa científica tanto quanto os dos 'outros'” (Fassin, 2008, pp. 337-341). Esta postura seria das que permitiria, ao contrário da militante e da aplicada, conferir "inteligibilidade aos discursos e interpretações aparentemente incompreensíveis" (Fassin, 2008, p. 339); quer dizer, realizar uma das tarefas canônicas da antropologia (Fassin, 2008, p. 336).

Será ainda pouco. Porque uma tal antropologia da moral se prenderá ao que é normativo, legal, do dever. Seria necessário, portanto, provocar um outro movimento: desistir do investimento moral, a saber, do que é regra, norma, lei (jural). Menor concentração no que as pessoas julgam que devem, maior no que elas avaliam que podem, é o passo que pretendo dar neste texto. Ou ainda, por outras 176 palavras, concentrar-se no modo como as pessoas empregam feixes de enunciados normativos de um modo tático e estratégico, muito mais do que entendê-las como meros pacientes dos códigos (morais, legais, culturais, sociais). Neste sentido, talvez não haja antropólogo que mais se tenha esforçado contra a ideia de um código que contenha informações capazes de provocar comportamentos do que Tim Ingold (2000), mesmo ou sobretudo quando esta ideia é transubstanciada na imagem de um programa. A questão, para nós, seria muito antes a de verificar etnograficamente o modo como se empregam enunciados normativos, regulamentares ou legais, do que avaliar se os comportamentos ajustam-se, desviam-se ou atacam a norma, o regulamento, a lei. Não seria exagerado invocar aqui mais uma vez um conceito foucaultiano: o de "gestão de ilegalismos"14. Já

\footnotetext{
${ }^{14}$ A noção de "ilegalismo" é uma substituição da oposição clássica entre legal e ilegal pela correlação entre ilegalismos-leis. As leis são, em Foucault, um agrupamen-
} 
não se trata, portanto, de uma lei que obriga, permite ou proíbe mas, antes, de modos de condução, gestão, sugestão. Argumentação e jogo, no lugar de coerção de um código transcendente sobre indivíduos caracterizados apenas por sua paciência.

\section{Pernambuco: primeira abordagem}

Pernambuco é relevante para a política nacional desde há mais de um século. Embora meus conhecimentos remontem apenas à Primeira República, trabalhos de historiadores mostram a importância central de diversos quadros políticos pernambucanos (Porto, 1986; Graham, 1997; Wiesebron, 1995). O que vale para o estado, antes e agora, vale para o Sertão. Alguns dos principais quadros políticos eram e são até hoje sertanejos. Ao mesmo tempo, considera-se de cabresto, de curral, clientelista, mercantilizado o modo como os meus colaboradores locais de pesquisa escolhem seus candidatos. Central e contemporâneo por um lado, periférico e atrasado, por outro, e simultaneamente, o Sudeste empurra para o passado o Nordeste, do mesmo modo como o Litoral pernambucano empurrava o Sertão para outro tempo ao longo da Primeira República (Villela, 2004).

Mas (essa é a questão, para mim), e se deixássemos que eles mesmos, os sertanejos, definissem para nós essas palavras? Trabalho de etnógrafo, básico. Se permitíssemos que o campo semântico fosse definido por suas práticas

to formalizador de "ilegalismos" ou, por outras palavras, formas de administração de ilegalismos que ela produz, com os quais transige, e, em certos casos, proíbe, "isola e toma como objeto, mas também como meio de dominação" (Deleuze, 1986, p. 36). A exposição a respeito do par "ilegalismo-delinquência" encontra-se em Foucault (1975, pp. 244 e ss.). Mas as primeiras referências à ideia de ilegalismo aparecem ainda em 1973 (Foucault, 1994a, pp. 435 e ss.). Cabe lembrar que em certas partes de sua obra Foucault explica a modificação dos regimes de punição pela via das modificações das gestões de ilegalismos correlativas, por sua vez (mas nem determinadas nem determinantes), de alguns modos de produção (Foucault, 1975, pp. 98-106). 
discursivas, explicativamente, para mim, e retoricamente, também para mim e em seus embates internos e externos? Se notássemos, por exemplo, que a criação dos animais ali é extensiva e os currais servem para protegê-los, e não para prendê-los? Que aquele é um mundo de pastores e não de agricultores? Isso não deveria mudar muito as ideias que alimentamos sobre o modo como os sertanejos fazem e pensam a política? Se imaginássemos, no que toca à mercantilização do voto, e como já notaram outros (Palmeira, 1992; Goldman, 2007), que compra e venda é um recurso de acusação volúvel, moralmente negativo, alvo da reprovação geral?

São muitas perguntas, experimentais, cujas setas apontam para muitos caminhos. Por conseguinte, tentarei manter meus argumentos num só lugar. Monografia. Retorno àquela experiência proposta acima: vejamos como se comportam os meus amigos (e seus conterrâneos meus des178 conhecidos, porque não conheço muitos dos que vejo e ouço em ação quando estou em campo) quando são postos do outro lado da vala cavada há tempos pelo pensamento social, pelas ciências sociais, pelos agentes estatais cujo objetivo é organizar, regular, vigiar e tornar lícitos os processos eleitorais que estes mesmos amigos pensam e agem há várias décadas. Prestar atenção nos recursos discursivos, nos atos de palavras, para que se saiba o que se faz ali com a gestão do dever, do legal, do normativo, do regular, do jural, enfim. Em síntese, verificar os usos atuais do dever, com a regra e com a lei ${ }^{15}$.

\section{Etnografia}

A parte que aqui se inicia é um breve relato do dia das eleições municipais realizadas em 5 de outubro de 2008

\footnotetext{
${ }^{15}$ Para uma exercício recente e original desta abordagem - que chama a atenção pelo cenário etnográfico em que se dá - ver Biondi (2009; 2010).
} 
em Jordânia, município situado no Sertão de Pernambuco, ou, mais precisamente, na mesorregião do São Francisco, microrregião de Itaparica. Pretendo, de um modo exclusivamente etnográfico, apresentar as relações da população em geral, mas também dos candidatos - entendidos antes como um coletivo do que como uma soma de cada um dos pleiteantes a um cargo eletivo - com a Justiça Eleitoral. Inegável, a mesma tensão poderia ser descrita para o caso das ONGs que visam conscientizar os eleitores sertanejos ao organizarem debates entre candidatos ao cargo de prefeito e divulgarem desde há duas eleições o slogan "voto não tem preço, tem consequência" e que é aproveitado por candidaturas que visam mudança e que se estruturam como terceira $v i a^{16}$. No entanto, entre candidatos, eleitores e ONGs deste tipo não verifiquei a ocorrência de confrontos de pontos de vista. Meus colaboradores locais acatam e concordam com as opiniões divulgadas e concordam com as suas próprias sobre política eleitoral sem que haja choque. Por este motivo privilegio aqui as relações entre candidatos, eleitores e Justiça Eleitoral.

Se por candidatos deve-se entender antes candidaturas (o coletivo que compõe o esforço para conquistar, por meio do acúmulo de votos, um ou diversos cargos eletivos), por Justiça Eleitoral quero dizer o conjunto das leis eleitorais e o seu funcionamento posto em marcha pela juíza e pela promotora da Comarca, mas também por um importante pedaço da população. Apesar de ter sido a terceira que

\footnotetext{
${ }^{16}$ Terceira via, expressão muito empregada atualmente no Sertão, refere-se às candidaturas novas, que se propõem inovadoras porque não pretendem fazer das eleições um momento de distribuição de recursos contra votos, e ainda por se proporem trazer uma proposta ética contra a corrupção, conscientizar os eleitores contra a exploração de que são objeto, distinguir o que é cunho propriamente político-administrativo do que é de toda outra ordem (parentesco, amizade), substituir a seletividade considerada nepotista ou política por uma outra, meritocrática ou tecnocrática. Nem todos estes argumentos são mobilizados por todas as terceiras vias e mesmo as que acionam todos eles não costumam fazê-lo de um só golpe.
} 
acompanho no Sertão de Pernambuco, a eleição municipal de 2008 foi a primeira em que tive a oportunidade de me aproximar e verificar de muito perto o trabalho das representantes da justiça junto aos candidatos e aos eleitores. $\mathrm{O}$ contato entre uns e outros permite descrever o choque de moralidades em meio aos ideais da democracia representativa, assim como as incompreensões mútuas acerca da lei em proveito da ética na política eleitoral. Será preciso recordar que não pretendo aqui contrapor práticas, discursos ou moralidades tradicionais às modernas. Os envolvidos nos choques descritos adiante, seus discursos e suas práticas, são atuais; contemporâneos, portanto.

Nestas eleições o colégio eleitoral de Jordânia era de cerca de 20 mil eleitores para uma população de mais ou menos 27 mil habitantes ${ }^{17}$. A pequena diferença entre população e eleitores não deve assustar. Não se trata, como se supõe sempre que o desconhecimento do que se fala é 180 grande, de fraude eleitoral. Tal diferença se explica pela ausência de inúmeros jordanenses que mantêm, por motivos diversos, seus registros em sua cidade natal e apenas circunstancialmente aproveitam as eleições para visitar seus parentes, participar da festa, rever amigos de quem há muito se separaram, ajudar algum candidato ao somar a outros o seu e os votos de seus familiares etc. Dos 20 mil eleitores apenas 17 mil compareceram, sendo que destes cerca de 1.500 votaram em branco ou nulo. A taxa de abstenção respeita os percentuais históricos para pleitos municipais: 14\% em 2008, 14\% em 2004, 18\% em 2000. Daí para trás o TRE/PE (2008) não fornece dados de abstenção. Cerca de 8 mil eleitores votaram no candidato vencedor e aproximadamente 7.600, no derrotado. Menos de quatrocentos votos decretaram a vitória do lado, ou da família ou ainda do partido que se viu derrotado a cada quatro anos, por

\footnotetext{
${ }^{17}$ Os dados são, respectivamente, do TRE/PE (2008) e do IBGE (2000-2001).
} 
oito vezes consecutivas. Desde 1976 os Santanas triunfaram sobre os Gouveias.

De onde eu participava destas eleições, até à noite da véspera do pleito, nada fazia suspeitar deste resultado. A diferença seria de 1.500 ou de mil votos, diziam todos, e até uma pesquisa não registrada em cartório garantia entre $10 \%$ e $12 \%$ de frente para o candidato dos Santana - ou seja, 1.700 ou 2 mil votos. Nesta noite, contudo, um experiente político dizia-se preocupado, enquanto recebia em sua casa alguns convidados de várias faixas etárias. Não vai ser de mais de quinhentos votos, ele garantia. Seu irmão, eu soube já após a derrota, falava em cem, no máximo duzentos votos. E, no entanto, o grosso das pessoas com quem eu participava do pleito não lhes deu ouvidos. E, para todos, a despeito da diferença prevista, a probabilidade de derrota era uma impossibilidade.

O dia 5 acordou ensolarado. Pronto para a festa. Fazia calor, mas havia a brisa de Jordânia que sopra desde o braço do rio Pajeú, que corre às suas costas rumo ao São Francisco. Saí às ruas trinta minutos depois das oito da manhã. A festa na noite anterior, a acolhida de improviso numa casa onde não estava hospedado e a espera para tomar o café da manhã com os donos me atrasaram um pouco. Ao chegar na rua em que se situa o fórum e a maior parte das seções eleitorais da sede municipal e, onde, por conseguinte, circulava o grosso dos eleitores que vieram votar, vi o mundo de camisas vermelhas diante de mim. Era a temida "onda vermelha" já sublinhada por mais de um correligionário dos Santanas. Mas havia muitas das camisas brancas com o rosto do prefeito Santana, há poucas semanas morto vítima de um infarto. Usar branco foi alvo de crítica porque, afinal, o vermelho é muito mais chamativo, aparece mais, diziam algumas pessoas, sobretudo mulheres. Eu estava de todo contagiado com o clima ao ponto de dirigir minha atenção em primeiro lugar ao maior problema de uma eleição: 
a quantidade. Ia chegando ao portão do fórum e tentava avaliar quem tinha mais camisas: o vermelho ou o branco? Impossível dizer, é claro, como sempre. A quantidade é sempre uma imprecisão.

Ao entrar no fórum constatei a calma. Não havia ninguém exceto os serventuários, a juíza e a promotora. Chamemo-las Eduarda e Márcia, respectivamente. A Dra. Márcia tinha acabado de chegar na cidade, dois dias antes. Tinha estado em Jordânia em 1992, no auge da grande questão que durante dez anos envolveu parentes de Santanas e Gouveias, vitimou mais de trinta pessoas - entre elas dois prefeitos Santanas (Marques, 2002). Publicizava para quem quisesse ouvir as suas teses sobre o lugar: "o problema daqui é que se mistura família com política e em toda eleição se tem medo de que as brigas voltem. O resto é tudo igual”. Mostrava-se experiente e servia de apoio moral e psicológico para a Dra. Eduarda, que vivia a sua primeira eleição 182 como juíza. A doçura de Eduarda contrastava com a dureza de Márcia; isso era notável nos comentários das pessoas que pude ouvir passando pelas ruas e de outras que se queixaram a mim diretamente.

Saí andando pelas ruas com meu caderninho na mão, sendo confundido com um jornalista em certos casos. Em outro, fui parado por um homem, que estava bêbado: "tá anotando palpite?”. Não, eu não era o apontador do jogo do bicho, respondi rindo junto com três moças que, sentadas numa amurada, testemunharam a cena. Longe da rua do fórum reinava a calma. Um candidato a vereador, sentado no portão de sua casa, era ladeado por três rapazes. É para não o matarem, diziam dois outros, distantes uns cem metros do lugar. Ainda adiante, numa praça em obras, duas ou três mulheres lavavam as suas calçadas, alheias ao vozerio fervilhante que ocorria a poucas dezenas de metros de suas portas.

Retomei o caminho de volta ao fórum. Vi um dos carros da justiça. O motorista parou e um dos passageiros me ofe- 
receu carona. Ainda da rua, perguntei se iam para a zona rural. Não agora, mas às onze horas. Eu perguntei se podia ir e, ao falar, notei que a Dra. Márcia estava no banco de trás. Disseram que sim e que eu esperasse no fórum, exatamente para onde me dirigia. Em Jordânia, juíza e promotora sempre se deslocam com escolta armada. Para onde quer que vão: almoçar, jantar, para o hotel. Neste caso, no banco da frente, estava um PM portando uma arma longa, um fuzil. Precaução, apenas, baseada na história recente do município, estigmatizadora do lugar e do povo.

Eu deveria esperar cerca de uma hora e resolvi passá-la toda no fórum. Logo ao chegar vi uma pequena aglomeração. Eram três crianças que vieram prestar queixa de um problema com os carros que transportam eleitores. Por outro lado, uma Gouveia, queixosa assídua dos desajustes eleitorais, estava indócil procurando a juíza ou a promotora para denunciar alguma coisa.

A denúncia das crianças aponta para três questões importantes nas eleições em cidades como Jordânia: a fiscalização, o denuncismo e os carros. É notável que três crianças tenham feito a denúncia. Os adultos também o fazem. E o fazem com frequência. Distribuição de dinheiro, de comida, de água, motorista que não deixa eleitor adversário entrar no carro, fiscal de coligação que faz boca de urna, gente distribuindo chapa, diretório cheio de gente. Tudo é motivo para queixa. E queixamse cabos eleitorais, candidatos, parentes de candidatos e de cabos eleitorais; queixam-se eleitores comuns; queixam-se, como vimos, as crianças. Porque em Jordânia cada eleitor é um fiscal. No dia das eleições, Jordânia transforma-se numa cidade vigilante. Cada um dos jordanenses é capaz de lançar mão do regulamento oficial do jogo em proveito próprio, ou de seu agrupamento político. É um recurso de tal modo frequente que as autoridades procuram refúgio desta avalanche de denúncias. 
Para denunciar é preciso que se produza fatos denunciáveis. Dizia-se que durante a última semana de campanha havia dois espiões de cada coligação em frente à casa de cada candidato a prefeito fazendo uso de uma filmadora e de uma câmera fotográfica. Os quatro prontos a flagrar um ato que pudesse impugnar a candidatura do opositor. Constatar ilegalidades eleitorais, com a vigilância, mas também produzi-las, enviando agentes disfarçados para as casas dos candidatos e para os diretórios políticos para fazer pleitos, como se costumava dizer antanho, quer dizer: fazer pedidos de medicamentos, pagamento de contas, cestas básicas, dinheiro ${ }^{18}$.

Mas não só para isso serve a vigilância. Ela equivale ainda à marcação homem a homem do melhor jogador adversário de modo a impedir o seu pleno rendimento durante um jogo. Impedir que se angarie votos por meio da distribuição ilegal de recursos é, portanto, o outro objetivo 184 da vigilância. No dia das eleições, aqueles que são identificados como trabalhadores para uma das candidaturas, sobretudo os sabidamente eficientes, são verdadeiramente marcados sob pressão, durante todo o dia, por um ou mais opositores. A tarefa dos marcadores é determinada em uma reunião na véspera, como faz um técnico na preleção do vestiário ("não deixa fulano andar", por exemplo, é modelo de enunciado que se toma de empréstimo diretamente do futebol para as eleições).

Portanto, ao contrário do que se poderia imaginar desde aqui do Sul, burlar a lei eleitoral para meus interlocutores de pesquisa é muito mais difícil do que transgredila aqui. Porque não são mais as autoridades, é um grosso pedaço da população a responsável pela vigilância. Mesmo

\footnotetext{
${ }^{18}$ A respeito dos pleitos ou pedidos, sobre a circulação de recursos nas eleições no Sertão, sobre o que os sertanejos consideram moralmente condenável (como a compra e a venda de votos, por exemplo) em contraposição ao voto consciente, ver Villela (2005) e Villela e Marques (2006).
} 
os mesários são vigiados e vigilantes de seus trabalhos e dos seus vizinhos. Porém, ao mesmo tempo, veremos, o rigor da lei escandaliza os jordanenses. Ela muitas vezes parece a eles uma prática de bárbaros. Uma prática que extirpa das pessoas o que elas têm de melhor. Uma prática muito imoralista. Pode-se pensar no encontro de uma moral tradicional que se escandaliza com as leis nacionais modernas (relativismo cultural); pode-se preferir apostar na incompreensão local da burocracia central (posição processualista). Mas pode-se entender que se tratam de articulações argumentativas do que está disponível para a efetuação de uma conduta ética: não mais um problema moral, legal e normativo. Lidamos, parece-me, com um problema de potência, tático ou estratégico, a saber, o que se pode fazer para realizar um objetivo desejável diante de determinadas circunstâncias?

Vejamos por exemplo o caso dos carros. Como se sabe, em lugares em que não há transporte público a justiça eleitoral requisita o serviço dos veículos contratados pela prefeitura e aceita a oferta dos candidatos que desejem colocar outros à disposição. Neste último caso, claro, o candidato, embora arque com as despesas, perde automaticamente o direito de designar os lugares para onde deseja enviar os carros como também os passageiros que pretende fazer embarcar. Os carros e os motoristas, desde que recebem as credenciais da justiça eleitoral, estão a seu serviço exclusivo. Os veículos não credenciados estão proibidos de circular com outras pessoas que não os seus parentes. Assisti à reunião convocada pela juíza e pela promotora com os motoristas dos carros credenciados. As orientações das duas foram recebidas com desconforto pela assistência, quando não com revolta contida. Desconforto, quando lhes foi anunciado que serviriam como fiscais da justiça e que deveriam denunciar toda atitude ilegal nos seus carros, como compra de votos e assédio a eleitores. Porque em todo carro 
poderia haver um fiscal de cada coligação para evitar que eleitores fossem impedidos ou privilegiados no embarque por conta de suas opções eleitorais ou de relações de amizade e de família. Mas os fiscais que se fiscalizariam entre si e que fiscalizariam o motorista deveriam ser fiscalizados por este último. Do contrário, o motorista do veículo seria responsabilizado criminalmente pelos delitos. "É crime federal", sublinhou em tom de ameaça a promotora. Foi como se um jato de criogênio tivesse sido lançado no ar abafado da sala. Como é que se poderia denunciar à justiça pessoas que vivem conosco? O problema não era apenas de ameaça física, mas de ameaça moral. E aqui o denuncismo convive com a rejeição à denúncia. Denunciar um opositor que numa hora de eleição vira inimigo, isso se pode fazer. Mas denunciar, às vezes, um compadre, um primo, um amigo? Quem poderia fazer isso, senão ao preço do desprezo público e da maledicência?

186 E, para agravar o problema, juíza e promotora advertiram que não se poderia dar nem comida nem água aos eleitores. Nesta hora, a revolta surda que reinava entre os motoristas ganhou voz. Negar água a uma pessoa com sede? A gente que às vezes vem de trinta ou quarenta quilômetros de distância, em estrada de pedra, areia e terra antes de pegar a pista de asfalto? Que tipo de desumanidade era essa? A revolta pode traduzir-se nas palavras de um amigo querido em sua casa na véspera do pleito, sentado à mesa e cercado de suas filhas: eu posso até ser preso, mas eu não vou negar um copo d'-água a quem venha pedir e nem um prato de comida. E, como me disse um advogado, na cidade, no dia da eleição: a promotora está obstruindo o livre exercício da cidadania pelas pessoas pobres que esperam receber transporte confortável para o seu local de votação e acolhimento - um lugar onde possam sentar, descansar, comer e beber. Por isso, ele considera, se deveria entrar com uma representação legal contra ela. 
Portanto, denúncia e rejeição à denúncia. A depender das circunstâncias disponíveis, denunciar passa a ser prejuízo para a realização de determinados objetivos que não necessariamente envolvem diretamente o que é eleitoral. Apenas não se envolver em conflitos em nome de pessoas cujo interesse gira exclusivamente em torno dos votos, esse era o objetivo de muitos dos motoristas obrigados a trabalhar gratuitamente durante todo o dia para a Justiça Eleitoral. Antes de mais nada porque se sabe muito bem a que tipo de paroxismos os conflitos pessoais e familiares podem chegar em Jordânia. Portanto, lança-se mão de um outro estoque para refutar o que é normativo e legal, neste caso, e não recorrer a ele, como no exposto logo acima, para o fato da vigilância e do denuncismo.

De volta ao fórum. Quase na hora de partirmos para a zona rural. Expressão muito ampla porque na verdade iríamos rumo a uma vila, histórica na região, por sua tradição, por sua fama de valentia. A partida atrasou, como tudo no mundo. Saímos quase ao meio-dia. Eu conhecia bem a estrada e a vila também. Tenho alguns amigos que moram lá. Trata-se de uma rua, uma alameda pela qual transitaram inúmeros personagens que visitam as páginas de diversos livros sobre o cangaço. De fato, não se pode falar de cangaço sem se falar dela, porque não se pode falar de Lampião sem se falar dela. E lá estavam eles, no dia 5 de outubro de 2008, os descendentes dos maiores inimigos do mais famoso bandido da história do Brasil. Lá estavam eles, ostentando a valentia dos seus pais e avós em suas performances atuais assim como ela foi solidificada em concreto no marco da praça no qual está escrito: monumento à vila de Carnaxide e aos homens que lutaram bravamente contra o banditismo no Nordeste.

"Quantos quilômetros até lá?”, perguntou a promotora. "42", disse o motorista. "Aaave Maria, 84 quilômetros ida e volta!”. Iria até lá, lamentava-se a doutora, por cau- 
sa das denúncias de distribuição de gasolina e de comida. Um lado (quer dizer, os membros locais de cada coligação) denunciou o outro e vice-versa. Carnaxide tem uma longa tradição na política de Jordânia. A alcunha de "Vila Cruel" que recebeu dos irmãos Ferreiras (um dos quais, Lampião) tornou-se adjetivo dos Santanas após seguidas derrotas sofridas lá. Nas últimas eleições venceram, avaliam muitos, por conta do trabalho eleitoral de um filho do lugar e neste ano confiavam outra vez na vitória pelo mesmo motivo. Achavam que perderiam na outra vila, a Raiz da Serra, pela desaparição sem substitutos das antigas lideranças locais. Seriam, contudo, e nos dois casos, contrariados pelos resultados das urnas.

Após a bela viagem em meio à caatinga ainda verdejante, resultado da boa invernada daquele ano, chegamos a Carnaxide. A vila estava tomada pelo povo. Era difícil transitar a pé sem esbarrar nos outros. De carro, era preciso abrir 188 caminho. O sol era esmagador, mas ninguém era intimidado pela quentura. A promotora saiu do carro e dirigiu-se incontinenti - como gostava de dizer - a uma casa, um dos alvos das denúncias. Eu segui em frente. Cheguei até outro aglomerado de gente. Era em frente a uma porta de aço fechada, alvo de outra denúncia. Na casa, era a distribuição de água. Na porta de aço, distribuição de combustível. O acusado era o marido de uma candidata à câmara, já vereadora e sempre a mais votada na vila. Mas eles próprios eram denunciantes da distribuição de lanches pelos adversários que disfarçaram o delito, diziam os queixosos, afixando na porta da casa onde a comida era fornecida o preço de $\mathrm{R} \$ 0,50$. Enquanto a chave da loja não aparecia, a vereadora propunha à promotora olhar o lugar antes que ele fosse ainda mais disfarçado. Dra. Márcia não dava ouvidos e esperou na porta até que a chave aparecesse. Era um depósito de combustível. Mas o dono tinha necessidade dele porque tinha seis carros que prestavam serviços ao grupo escolar 
e não havia um posto por perto; ele tinha de ter meios de fazer seus carros andarem. Não ficou provado nada, ninguém foi legalmente punido.

$\mathrm{O}$ advogado opositor da vereadora, irmão do tal cabo eleitoral que, como consideram alguns, dera a vitória na vila aos Santana em 2004, era o denunciante tanto para o caso da água, quanto para o de combustível. Ele era, por sua vez, acusado por diversas pessoas de traição. Mas traição a quem? Isso não foi dito dessa forma, mas se tratava de uma traição à vila e, por extensão, à sua família. Dizia-me uma mulher, mesmo antes de saber quem eu era, que ela não acreditava que um menino que ela viu crescer, "ali, tudo junto, tudo parente", podia estar filmando o tio para denunciá-lo à justiça. Ela então se virou para ele mesmo e perguntou se não tinha vergonha de fazer uma coisa daquelas. Ele fez ouvidos moucos, embora ela insistisse na pergunta. Diante da negativa de resposta, virou-se para a promotora e se disse incrédula por terem chamado uma autoridade para tão longe por motivo nenhum.

Mas, e a água? Com aquele calor, como é que podiam negar água ao povo? "Ponham a água no muro e deem a todos que passarem pela porta, sem distinguir se é eleitor de José ou de João". Foi a solução salomônica encontrada pela promotora. Sabida ou ignorante, ela negligenciou, inocente ou dissimulada, o fato óbvio para todos os presentes de que jamais um eleitor se aproximaria para beber da água fornecida por um opositor (atitude moralmente qualificada como "coisa de cabra safado, gente sem vergonha", que pede coisas a um candidato e vota em outro. Ou, enfim, de gente que vende o voto). Mas o marido da vereadora entrou em casa e reapareceu ostentando uma leiteira de alumínio cheia d'água e gritava: "Quem quer água, olha a água, venham beber!”. Enquanto agitava a mão esquerda. Do outro lado, o advogado adversário, seu primo, dizia à promotora: "Ele faz isso para provocar. É uma provocação a nós e à justiça”. 
E a comida? Como é que não se vai dar de comer? Não é só um problema moral - o de negar comida a quem pede. É também um problema de logística: "Nós recebemos os nossos parentes que vêm do mato. Sempre foi assim. A gente fazia aquelas panelas enormes de mungunzá e vinha aquela gente toda comer". "Lá em casa também era assim", acrescenta um senhor que, também antes de me conhecer, corrobora a queixa da mulher revoltada com o primo que a espiona e a denuncia para a justiça. Uma amiga que mora desde seu casamento há sessenta anos em outro município, de cujo nome lanço mão para me apresentar a meus interlocutores de Carnaxide, me contou também, em outro ambiente e em outro dia, a mesma coisa: era a festa. "Tinha muita comida, a gente que era nova gostava de ir cedo, mas só voltava na boquinha da noite". E se votava por último para demorar mais a perder o prestígio, mas também para não ser logo encaminhado para o carro que os levaria de 190 volta para o mato, quer dizer, para a zona rural, longe da vila. Se era festa, era preciso ter comida, distribuição de comida. E, afinal, eram todos parentes. Como é que se pode negar comida aos parentes? A justiça aceita, disse a promotora na reunião com os motoristas, que alguém conduza em seu carro, mesmo não credenciado, os seus parentes. Mas, para o nosso caso, como definir quem é e quem não é parente? Pode-se levar, ela disse, quem é da sua família. E eu pensei, lá com os meus botões e me controlando para manter dentro da boca a minha língua grande, o que se entende, que definição se deverá assumir, para família e para parente. E quais serão os critérios para decidir se um comensal é ou não é parente do anfitrião? O biológico? O da consanguinidade? $\mathrm{O}$ ritual? $\mathrm{O}$ de contágio? Ninguém perguntou. Ninguém respondeu.

Em meio a tantos problemas, a promotora vez por outra era engolida pelas práticas e pela retórica locais que, assim como ela procurava fazer, punham a seu modo em funcio- 
namento a legislação eleitoral. Ela dobrou-se em muitos casos à prática local e sua intransigência inicial em relação à letra fria da lei foi dando lugar à maleabilidade. Ela achou que inibiria o modo local de fazer funcionar a lei mostrando inflexibilidade: "É só a gente prender um candidato que todo mundo morre de medo e respeita a lei. O problema aqui”, seguiu, como que modulando para ela mesma, em voz alta, a reflexão, "é que é difícil distinguir o militante do eleitor". Concordo, tanto para um caso quanto para o outro. Mas para a última parte, ela diria, é o lado que atrapalha o exercício da letra da lei, porque, afinal, como é possível reprimir práticas que para os militantes são ilegais, mas que para os eleitores são legais e legítimas - ou vice-versa - sem que se saiba, afinal, quem é quem?

Todavia, isso ela não notou, também se tem dificuldade de distinguir os fiscais dos eleitores, já que cada eleitor é um fiscal da candidatura adversária. Mesmo que, não custa retomar, a denúncia à justiça receba tanto um sinal positivo quanto um negativo, a depender das circunstâncias estabelecidas pelas relações entre denunciado e denunciante e pelo acionamento da moral local pelas diversas retóricas disponíveis no lugar - denunciar parente, denunciar adversário, por exemplo. E, para a primeira parte, também é verdade que a justiça do Estado nacional, para as pessoas entre as quais faço pesquisa, é temida e respeitada. É verdade que se faz política e eleição de olho nela; enviar advogados para cursos de atualização na lei eleitoral e cercar-se deles durante o pleito são apenas dois dos muitos signos desta deferência. Mas é verdade também que é preciso tentar ludibriá-la. É verdade que, conforme criticou uma de minhas mais próximas amigas durante a última reunião no diretório dos Santanas, não se pode aceitar essa obediência servil à promotora porque assim se perde a eleição. Afinal, nunca "ninguém agiu de uma forma tão cordata quanto nós estamos agindo neste 
ano", finalizou ela, desde o alto de décadas de observação e atuação na política de Jordânia.

\section{Antropologia das relações de poder}

Os habitantes do Sertão de Pernambuco sabem como funciona a democracia e procuram agir de acordo com este seu saber. As eleições por lá foram muitas e ocorrem, salvo por pequenos intervalos, continuamente há mais de um século. Por isso, foram capazes de estabelecer, entre práticas e discursos, um conjunto moral; decerto cambiante com o tempo, como eles próprios, com prazer ou com desgosto, são capazes de reconhecer. Mas este conjunto moral é antes um arsenal de onde se pode retirar armas e projéteis que visam a constituição de uma ética. Nesta chave, já não se trata mais do regular, do normativo e do legal; mas da potência, das relações de poder e de luta que se estabelecem entre eleitores e candidatos, entre candidatos e candidatos, entre estes

192 e os serventuários da justiça, dos trabalhadores de ONGs etc. No caso de política eleitoral, a luta é, como se sabe, para obter um cargo eletivo. Parece-me que os sertanejos não abrem mão de produzir uma moral para a política, mas ela é cambiante e submetida às relações de poder, de disputa e de luta. Ela não é um código moral, universalizável, fixo, essencializado. É lábil, assim como o balanço das eleições e da política.

Uma antropologia das moralidades é falha quando relativiza os outros costumes e experiências de agrupamentos distantes. Completar esta tarefa, a da constituição de uma antropologia das moralidades, requer a relativização dos aspectos centrais da nossa sociedade. O que nos trás de volta ao complexo problema do relativismo moral. Porque, afinal - e Carrithers (2005) não responde este problema -, o relativismo moral é moralmente condenável? $\mathrm{O}$ máximo que se consegue depreender de seu artigo é que ele nos lança numa "incerteza moral" (Carrithers, 2005, 
p. 445). Ou, por outras palavras, as dele, a constatação da diversidade imprevisível de valores morais das diferentes culturas (Carrithers, 2005, p. 435), acarreta a convicção de um campo indiferenciado de incertezas. O problema epistemológico, o da equivalência indiferenciada provocada pelo relativismo, transborda para um problema de moral cidadã. Seria preciso, portanto, identificar uma escapatória ao problema do absolutismo moral; um espectro situado no umbral da evitação do seu oposto, o relativismo. Será preciso uma alternativa que não obrigue os antropólogos, outra vez, a situarem-se do lado de cá dos dois mundos que forjaram a sua disciplina.

O caso da democracia representativa é apenas um dentre muitos privilegiados para este exercício antropológico (a Ciência, os Direitos Humanos e todos os outros universais são os primeiros nomes de uma lista extensa). Relativizá-los, ou seja, relativizar o nosso próprio mundo (ou que o compõe como é), ao mesmo tempo é dar à antropologia a ousada face desocidentalizada de que ela precisa em certos casos. Esta tarefa não é nova: ela compõe o esforço antropológico da obra de Michel Foucault. Neste sentido, o projeto da antropologia das relações de poder teria de acompanhar aquela de Foucault: uma antropologia intempestiva, inatual, contra o seu tempo. Mas não rumo ao indiferenciado relativo de todas as coisas. Rumo a uma crítica do nosso tempo, de nossos saberes, de nossos poderes.

Capaz de desfazer simultaneamente duas ilusões muito difundidas, interessa o Sertão de Pernambuco pela capacidade de revelar a democracia representativa como apenas um ideal que não se realiza em parte alguma (Veyne, 1984) e que, portanto, é composto apenas de variações (não apenas a indiana ou a brasileira, mas a francesa, a inglesa, a americana etc.); de dissipar a ideia muito difundida de que as até então chamadas variações são o fruto da execução presente dos ideais democráticos por populações pretéritas 
(por outras palavras, tradicionais), incapazes ou impedidas de realizá-los plenamente. Assim, o estilo etnográfico decorrente do trabalho intensivo de campo, de posse de uma antropologia das relações de poder, talvez seja um dos instrumentos mais eficazes para que se dissolva um conjunto importante de ideias políticas inadequadas.

\section{Jorge Mattar Villela}

é professor do Programa de Pós-Graduação em Antropologia Social da UFSCar.

\section{Referências bibliográficas}

ABÈLES, M. [2000] 2001. Un ethnologue à l'Assemblée. Paris: Odile Jacob. . [1991] 2002. "Avoir du pouvoir politique”. In: SEGALEN, M. (org.)

Jeux de familles: parents, parente, parentèle. Paris: Presses du CNRS.

ABU-LUGHOD, L. 2002. "Do Muslim women really need saving? Anthropological reflection on cultural relativism and its others". American anthropologist, no 104, vol. 3, pp. 783-790.

ALMEIDA, M. s. d. "Caipora, mandioca e conflitos da ontologia política". (mimeo).

ARETXAGA, B. 2000. "A fictional reality: paramilitary death squads and the construction of state terror in Spain”. In: SLUKA, J. (org.). Dead squad: the Anthropology of State terror. Philadelphia: University of Pennsylvania Press.

BANTON, M. (org.). 1966. The social anthropology of complex societies. London: Tavistock.

BIONDI, K. 2009. Junto e misturado: imanência e transcendência no PCC. Dissertação de mestrado em Antropologia. São Carlos: PPGAS/ UFSCar.

2010. Junto e misturado: uma etnografia do PCC. São Paulo: Terceiro Nome.

BOISSEVAIN, J.; MITCHELL, J. C. 1973. Network analysis: studies in human interaction. Paris/The Hague: Mouton.

BURAWOY, M.; VERDERY, K. 1999. Uncertain transition: ethnographies of change in the postsocialist world. New York: Rowman e Littlefield.

CANDIDO, A. 1951. "The Brazilian family”. In: SMITH, T. L.; MARCHANT,

A. (orgs.). Brazil: portrait of a half continent. New York: Dryeden Press.

CARRIER, J. 1995. "Maussinan occidentalism: gift and commodity sys- 
tems". In: CARRIER, J. (org.). Occidentalism: images of the West. Oxford: Clarenton.

CARRITHERS, M. 2005. "Anthropology as a moral sciences of possibilities”. Current anthropology, vol. 46, n 3, pp. 433-456.

CHAVES, C. 2003. Festa na política: uma etnografia da modernidade no sertão (Buritis - MG). Rio de Janeiro: Relume-Dumará.

COMMAROFF, J. L.; COMAROFF, J. 1997. "Postcolonial politics and discourses of democracy in Southern Africa political modernities". Journal of anthropological research, vol. 53, $\mathrm{n}^{\circ}$ 2, pp. 123-146.

CORRÊA, M. 1994. "Repensando a família patriarcal brasileira". In: Colcha de retalhos: estudos sobre a família do Brasil. Campinas: Ed. Unicamp.

DELEUZE, G. 1986. Foucault. Paris: Minuit.

DONZELOT, J. 1986. A polícia das famílias. Rio de Janeiro: Graal.

DUARTE, N. [1939] 1966. A ordem privada e a organização política nacional. São Paulo: Companhia Editora Nacional.

EISENSTADT, S. N.; RONIGER, L. 1984. Patrons, clients and friends: interpersonal relations and the structure of trust in society. Cambridge: Cambridge University Press.

FABIAN, J. 1983. Time and the other: how Anthropology makes its object. New York: Columbia University Press.

FASSIN, D. 2008. "Beyond good and evil? Questioning the anthropological discomfort with morals". Anthropological theory, vol. 8, $\mathrm{n}^{\circ}$ 4, pp. 225-246.

FOUCAULT, M. 1975. Surveiller et punir: naissance de la prison. Paris: Gallimard.

1978. A verdade e as formas jurídicas. Rio de Janeiro: PUC.

. [1976] 1985. História da sexualidade I: a vontade de saber. Rio de Janeiro: Graal.

. [1973] 1994a. "À propos de l'enfermement pénitentiaire". In:

DÉFERT, D.; EWALD, F. (orgs.). Dits et écrits. Paris: Gallimard. . [1974] 1994b. "De la nature humaine: justice contre pouvoir". In: DÉFERT, D.; EWALD, F. (orgs.). Dits et écrits. Paris: Gallimard. . [1982] 1994c. "Verité, pouvoir et soi". In: DÉFERT, D.; EWALD, F. (orgs.). Dits et écrits. Paris: Gallimard.

. [1982] 1994d. "Tecnologie politique des individues". In: DÉFERT, D.; EWALD, F. (orgs.). Dits et écrits. Paris: Gallimard. 1997. Il faut défendre la société: Cours au Collège de France (1976).

Paris: Gallimard/Seuil.

. 2001. Herméneutique du sujet. Cours au Collège de France (1981-1982). Paris: Gallimard/Seuil. 
2004a. Sécurité, territoire, population. Cours au Collège de France (1977-1978). Paris: Gallimard/Seuil.

2004b. Naissance de la biopolitique. Cours au Collège de France (1978-1979). Paris: Gallimard/Seuil.

FREYRE, G. 1964. "The patriarcal basis of Brazilian society”. In: MAYER, J.; WEATHERLEAD, R. W. (orgs.). The politics of change in Latin America. New York: Praeger.

GARRIGOU, A. 1988. Le vote et la vertu: comment les français sont devenus électeurs. Paris: Presses FNSP.

GEERTZ, C. 1963. "The integrative revolution: primordial sentiments and civil politics in the New States”. In: GEERTZ, C. (org.). Old societies and new States: the quest for modernity in Asia and Africa. New York: Free Press.

GELLNER, E.; WATERBURY, J. (orgs.). 1977. Patrons and clients in Mediterranean societies. London: Duckworth.

GERSHIÈRE, P. [1995] 1997. The modernity of witchcraft: politics and the occult in postcolonial Africa. Charlotteville: University of Virginia Press.

GOLDMAN, M. 2007. Como funciona a democracia: uma teoria etnográfica da política. Rio de Janeiro: Sete Letras.

GRAHAM, R. [1991] 1997. Clientelismo e política no Brasil do século XIX. Rio de Janeiro: Ed. UFRJ.

196 HERZFELD, M. 1985. Poetics of manhood: constest and identity in a Cretan town. Princeton: Princeton University Press.

. Social production of indiference: exploring the simbolic roots of Western bureaucracy. Chicago: Chicago University Press.

INGOLD, T. 2000. The perception of environement: essays in livehood, dwelling and skill. Londres: Routledge.

JANKOWSKI, M. S. 1991. Islands in streets: gangs and American urban society. Berkeley: University of California Press, 1991.

JULLIEN, F. [1995] 2001. Fundar a moral: diálogo de Mêncio com um filósofo das Luzes. São Paulo: Discurso.

. 2008. De l'universel, de l'uniforme, du commun et du dialogue entre les cultures. Paris: Fayard.

KUPER, A. 1988. The invention of primitive society: transformation of an illusion. New York: Routledge.

LEAL, V. N. [1949] 1997. Coronelismo, enxada e voto: o município e o regime representativo no Brasil. Rio de Janeiro: Nova Fronteira.

LEMIEUX, V. 1970. "Le patronage politique dans l'île d'Orléans". L'Homme, Paris, vol. 10, $\mathrm{n}^{\circ}$ 2, pp. 22-44.

MARQUES, A. C. 2002. Intrigas e questões: vingança de família e tramas sociais no sertão de Pernambuco. Rio de Janeiro: Relume-Dumará. 
2003. "Política e questão de família". Revista de Antropologia, São Paulo, vol. 45, no 2, pp. 417-442.

; COMERFORD, J.; CHAVES, C. 2007. "Traições, intrigas, fofocas, vinganças”. In: MARQUES, A. C. (org.). Conflitos, política e relações pessoais. Campinas: Pontes.

MAYER, J.; WEATHERLEAD, R. W. (orgs.). 1964. The politics of change in Latin America. New York: Praeger.

MICHELUTTI, L. 2007. "The vernacularization of democracy: political participation and popular politics in North India”. Journal of the Royal Anthropological Institute, vol. 13, n 3, pp. 639-656.

NATHAN, T. 2001. Nous ne sommes pas seules au monde. Paris: Seuil.

NuAP. 1998. "Uma Antropologia da política. Rituais, representações e violência: projeto de pesquisa". Cadernos do NuAP, Rio de Janeiro, $\mathrm{n}^{\circ} 1$.

OVERING, J. 1985. Reason and morality. New York: Tavistock.

PALEY, J. 2002. "Toward an Anthropology of democracy". Annual review of anthropology, vol. 31, pp. 469-496.

PALMEIRA, M. 1992. "Voto: racionalidade ou significado?". Revista brasileira de ciências sociais, São Paulo, vol. 7, n 20, pp. 26-30.

1996. "Política, facções e voto". In: PALMEIRA, M.; GOLDMAN, M. (orgs.). Antropologia, voto e representação política. Rio de Janeiro: Contra Capa.

; HEREDIA, B. 1993. "Le temps de la politique". Études rurales, Paris, vol. 131-132, pp. 73-88.

PANDOLFI, D. 1986. “As eleições em Pernambuco de 1950 a 1954". In: LAVAREDA, A.; SÁ, C. (orgs.). Poder e voto: luta política em Pernambuco. Recife: Massangana.

PORTO, C. 1986. Os tempos da República Velha. Recife: Fundarpe.

QUEIROZ, M. I. P. 1976. "Coronelismo numa interpretação sociológica”. In: Mandonismo local na vida política. São Paulo: Alfa-Ômega.

SCHIRMER, J. 1998. The Guatemalan military project: a violence called democracy. Philadelphia: University of Pennsylvania Press.

SCHMITT, W.; GUASTI, L.; LANDÉ, C.; SCOTT, J. (orgs.). 1977. Friends, followers and factions. Berkeley: University of California Press.

SCHNEIDER, P.; SCHNEIDER, J. 2008. "Anthropology of crime and criminalization”. Annual review of anthropology, vol. 37, pp. 351-373.

SLUKA, J. 1995. "Reflections on managing danger in fieldwork: dangerous Anthropology in Belfast”. In: NORDSTROM, C.; ROBBEN, A. C. (orgs.). Fieldwork under fire: contemporary studies of violence and survival. Berkeley: University of California Press. 
STOCKING JR., G. 1968. "Franz Boas and the culture concept in historical perspective". In: Race, culture and evolution. Chicago: University of Chicago Press.

SWARTZ, M. J. 1968. Local-level politics: social and cultural perspectives. Chicago: Aldine.

SWARTZ, M.; TURNER, V.; TUDEN, A. (orgs.). 1966. Political anthropology. Chicago: Aldine.

TAMBIAH, S. 1996. Leveling crowds: ethnonationalism conflicts and collective violence in South Asia. Berkeley: University of California Press.

TAYLOR, J. 1993. "The outlaw State and the lone rangers". In: MARCUS, G. E. (org.). Perilous States: conversations on culture, politics, and nation. Chicago: University of Chicago Press.

TAYLOR, A.-C. 2006. "Devenir Jivaro: le statut de l'homicide guerrier en Amazonie". Cahier d'anthropologie sociale, Paris, n' 2, 2006, pp. 67-84 (Especial: "La guerre en tête").

VEYNE, P. 1984. "Os gregos conheceram a democracia?”. Diógenes, Brasília, vol. 6, pp. 57-62.

VILLELA, J. M. 2004. O povo em armas: violência e política no sertão de Pernambuco. Rio de Janeiro: Relume Dumará.

. 2005. "Dinheiro e suas diversas faces nas eleições municipais em Pernambuco". Mana, Rio de Janeiro, vol. 11, n 1, pp. 267-296. . no prelo. "Família como grupo? Política como agrupamento? O sertão de Pernambuco no mundo sem solidez”. Revista de antropologia, São Paulo.

VILLELA, J.; MARQUES, A. 2006. "Municipal elections: favor, vote, and credit in the Pernambucan Sertão of Brazil". The latin americanist, vol. 49, $\mathrm{n}^{\circ}$ 2, pp. 25-63.

WEST, Harry. 1998. "Traditional authorities and the Mozabican transition to democratic governance”. In: GRAYBILL, L. G.; THOMPSON, K. W. (orgs.). Africa's second wave of freedom. Lanham: University Press of America.

WIESEBRON, M. 1995. "Elecciones en el Brasil 1880-1900: Bom Jardim y Afogados de Ingazeira (Pernambuco). Relación del poder local con el poder estatal”. In: ANNINO, A. (org.). Historia de las elecciones en Iberoamerica: siglo XIX. México: Fondo de Cultura Económica.

YANS-MCLAUGHLIN, V. 1986. "Science, democracy, and ethics: mobilizing culture and personality for World War II". In: STOCKING JR., G. (org.). Malinowski, Rivers, Benedict and others: essays on culture and personality. Madison: University of Wisconsin Press.

YASHIN-NAVARO, Y. 2007. "Make-believe papers, legal forms and the counterfeit”. Anthropological theory, n ${ }^{\circ}$, vol. 1, pp. 79-98. 
2009. "Affective spaces, melancholic objects: ruination and the production of anthropological knowledge". Journal of the Royal Anthropological Institute, vol. 15, $\mathrm{n}^{\circ}$ 1, pp. 1-18.

ZULAIKA, J. 1995. "The anthropologist as terrorist". In: NORDSTROM, C.; ROBBEN, A. C. (orgs.). Fieldwork under fire: contemporary studies of violence and survival. Berkeley: University of California Press.

\section{Outros materiais:}

BANERJEE, M. 1999. "Democracy, an Indian variant". Disponível em $<$ http://les1.man.ac.uk/sa/Mai99PolAnthPapers/Mukulika\% 20 Banerjee.htm>. Acesso em: 20/10/2009.

IBGE - INSTITUTO BRASILEIRO DE GEOGRAFIA E ESTATÍSTICA. 2000-2001. Disponível em <http://www.ibge.gov.br/home>. Acesso em: 12/11/2009.

TRE/PE - TRIBUNAL REGIONAL ELEITORAL DE PERNAMBUCO TRE/PE. 2008. Disponível em <http://www.tre-pe.gov.br>. Acesso em: $12 / 11 / 2009$. 


\section{MORAL DA POLÍTICA E ANTROPOLOGIA DAS RELAÇÕES DE PODER NO SERTÃO DE PERNAMBUCO}

JORGE MATTAR VILLELA

$\mathrm{O}$ artigo pretende elaborar uma reflexão acerca dos problemas enfrentados pelos antropólogos (e profissionais congêneres) quando se trata de tomar como proposição de pesquisa temas, atividades, atos e palavras que atingem o âmago do nosso sistema moral. O que fazer quando estudamos pessoas consideradas criminosas em nosso mundo? O que fazer quando estudamos questões centrais como a ciência, a democracia, a justiça, os direitos humanos? Com o auxílio 242 de uma situação etnográfica em que representantes da justiça eleitoral chocam-se com usuários contumazes da democracia representativa, procura-se mostrar as dificuldades de compreensão entre os dois conjuntos e a complexidade da circunstância em que duas partes entram em comunicação sem que uma entenda perfeitamente o idioma da outra. Ambas, contudo, parecem alimentar duas confianças: a de compreenderem a língua do interlocutor e a superioridade da sua própria. A ideia geral do artigo é que este recurso etnográfico possa fazer-nos abrir mão tanto do absolutismo quanto do relativismo moral.

Palavras-chave: Antropologia; Etnografia; Moral; Política; Poder.

\section{MORAL OF POLITICS AND ANTHROPOLOGY OF POWER'S RELATIONSHIPS IN PERNAMBUCO}

The article intends to produce a reflection on the problems faced by anthropologists (and professional peers) when it comes to taking 
the theme of research topics, activities, actions and words that reach deep into our moral system. What to do when we study people considered criminal in our world? What to do when we study key issues such as science, democracy, justice, human rights? With the help of an ethnographic circumstance in which representatives of electoral justice clash with habitual users of representative democracy, I tried to show the difficulties of understanding these two sets and the complexity of the situation in which two parties enter into a communication without fully understanding the other language. Both, however, seem to feed two trusts: to understanding the language of the speaker and the superiority of their own. The general idea of the article is that this feature ethnographic can make us give up so much of absolutism and moral relativism.

Key-words: Anthropology; Ethnography; Moral; Politics; Power. 